\title{
Operator-Controlled Comparison Between 5 French and 6 French Guiding Catheters for Percutaneous Intervention Using Transradial Approach
}

Hisham Hirzallah ${ }^{1}$, Kanaan Mansoor ${ }^{2}$, Ahmed Amro ${ }^{1}$, Julia Parsons ${ }^{2}$, Mohamed S. Suliman ${ }^{2}$, Damir Kusmic $^{2}$, Yasir Jawaid ${ }^{2}$, Yazan Numan ${ }^{2}$, Sutoidem M. Akpanudo ${ }^{2}$, Ellen Thompson ${ }^{1}$

1. Cardiology, Marshall University Joan C. Edwards School of Medicine, Huntington, USA 2. Internal Medicine, Marshall University Joan C. Edwards School of Medicine, Huntington, USA

Corresponding author: Mohamed S.Suliman,_mohamed_suliman@icloud.com

\section{Abstract \\ Objective}

To compare 5 French (Fr) and 6 Fr guiding catheters regarding the volume of contrast administered, fluoroscopy time, and total procedure time during transradial percutaneous coronary intervention (PCI).

\section{Background}

Previous studies had compared 5 Fr and 6 Fr catheters and deemed 5 Fr catheters safe and effective. In this study, we retrospectively compared the $5 \mathrm{Fr}$ catheter to $6 \mathrm{Fr}$ catheter with an attempt to eliminate the effect of inter-operator skill level variability.

\section{Methods}

In a single-center, retrospective cohort study, we randomly selected patients who had received PCI through transradial access using $5 \mathrm{Fr}$ or $6 \mathrm{Fr}$ catheters. The study involved two groups of 100 patients each. These groups were comprised of an equal number of cases from each operator. The primary endpoint was contrast medium volume. Secondary endpoints were fluoroscopy time and procedure time.

\section{Results}

Less contrast was used in the 5 Fr group vs. 6 Fr catheter group $(140.2 \pm 45.7 \mathrm{~mL}$ vs. $158.2 \pm 66.7 \mathrm{~mL}$, $\mathrm{p}=0.004)$. PCI using $5 \mathrm{Fr}$ catheters was associated with shorter fluoroscopy time $(13.7 \pm 7.3 \mathrm{mins}$ vs. $15.2 \pm 8.2$ mins, $p=0.584)$ and shorter procedure time $(43.7 \pm 22.2$ mins vs. $46.5 \pm 19.7$ mins, $p=0.890)$, but this was not statistically significant.

Received 05/14/2020

Review began 05/21/2020 Review ended 05/21/2020 Published 06/02/2020

๑) Copyright 2020

Hirzallah et al. This is an open access article distributed under the terms of the Creative Commons Attribution License CC-BY 4.0., which permits unrestricted use, distribution, and reproduction in any medium, provided the original author and source are credited.

\section{Conclusion}

Transradial PCI using 5 Fr guiding catheters was associated with less contrast medium usage, but there was no advantage regarding procedure time or fluoroscopy time when compared to $6 \mathrm{Fr}$ catheters. Similar to $6 \mathrm{Fr}$ catheters, 5 Fr catheters achieved high PCI success rates through radial access when compared in the treatment of coronary lesions with the same level of complexity.

\section{Categories: Cardiology}

Keywords: percutaneous coronary intervention, heart catheterization, 5 french catheters, 6 french catheters, transradial, radial access, contrast

\section{Introduction}

Since its inception in 1978, the field of percutaneous coronary intervention (PCI) has been evolving to constantly better itself [1]. Constant innovation in the field has led to a decrease in complication rates and improvement in the efficacy of the procedures. Much of the innovation has been directed towards the development of new equipment, specifically guiding catheters. Initially, 9-10 French (Fr) catheters were used for procedures; however, there was a gradual reduction in the size of catheters, and, eventually, $6 \mathrm{Fr}$ catheters were established as the standard of care. In 1989, a 5 Fr catheter was utilized for a coronary angioplasty for the first time.

Among the numerous medical devices manufactured, only a few make the cut and are deemed to be the standard of care after being studied and tested in the field. Before the $6 \mathrm{Fr}$ catheter was determined to be the standard of care, it had also been compared and tested against $7 \mathrm{Fr}$ and $8 \mathrm{Fr}$ catheters; and it was crowned as the standard of care only after it was deemed to be effective [2-4]. With the advent of the 5 Fr catheter, a 


\section{Cureus}

similar approach was undertaken before its utility was established in common practice. The question that arises with the advent of every new generation of modern catheters is whether or not it is as effective as its predecessor, particularly regarding its ability to deliver the necessary components such as balloons and stents during PCI. In this study, we retrospectively compared the $5 \mathrm{Fr}$ catheter to its predecessor, the $6 \mathrm{Fr}$ catheter, with an attempt to eliminate the effect of inter-operator skill level variability.

\section{Materials And Methods}

\section{Study design and patient population}

Our study was a single-center, retrospective cohort study designed to compare procedural variables of $5 \mathrm{Fr}$ versus 6 Fr catheters in patients who underwent PCI using radial access. A total of 200 patients were involved in the retrospective analysis in this study. The study population was randomly selected from a pool of 463 patients that included all the consecutive PCI cases performed at St. Mary's Medical Center - Marshall University by four different interventional cardiologists with expertise in transradial procedures during May 2016-May 2017. All of the cases used radial access as initial access, and at least one stent was deployed using $5 \mathrm{Fr}$ or $6 \mathrm{Fr}$ as an initial catheter. Indications for the procedure were either elective for stable angina or emergent for non-ST-elevation myocardial infarction (NSTEMI) and ST-elevation myocardial infarction (STEMI). The total study population was then divided into two groups: 5 Fr group and 6 Fr group. Of the total 463 cases that we considered, 265 were performed using 6 Fr catheter and 198 using 5 Fr catheter. Each of these two groups was then divided into four subgroups based on the operator (Figure 1). Twenty-five cases were randomly selected from each operator to be included in the study, resulting in the final two groups having 100 patients each with an equal proportion from each operator.

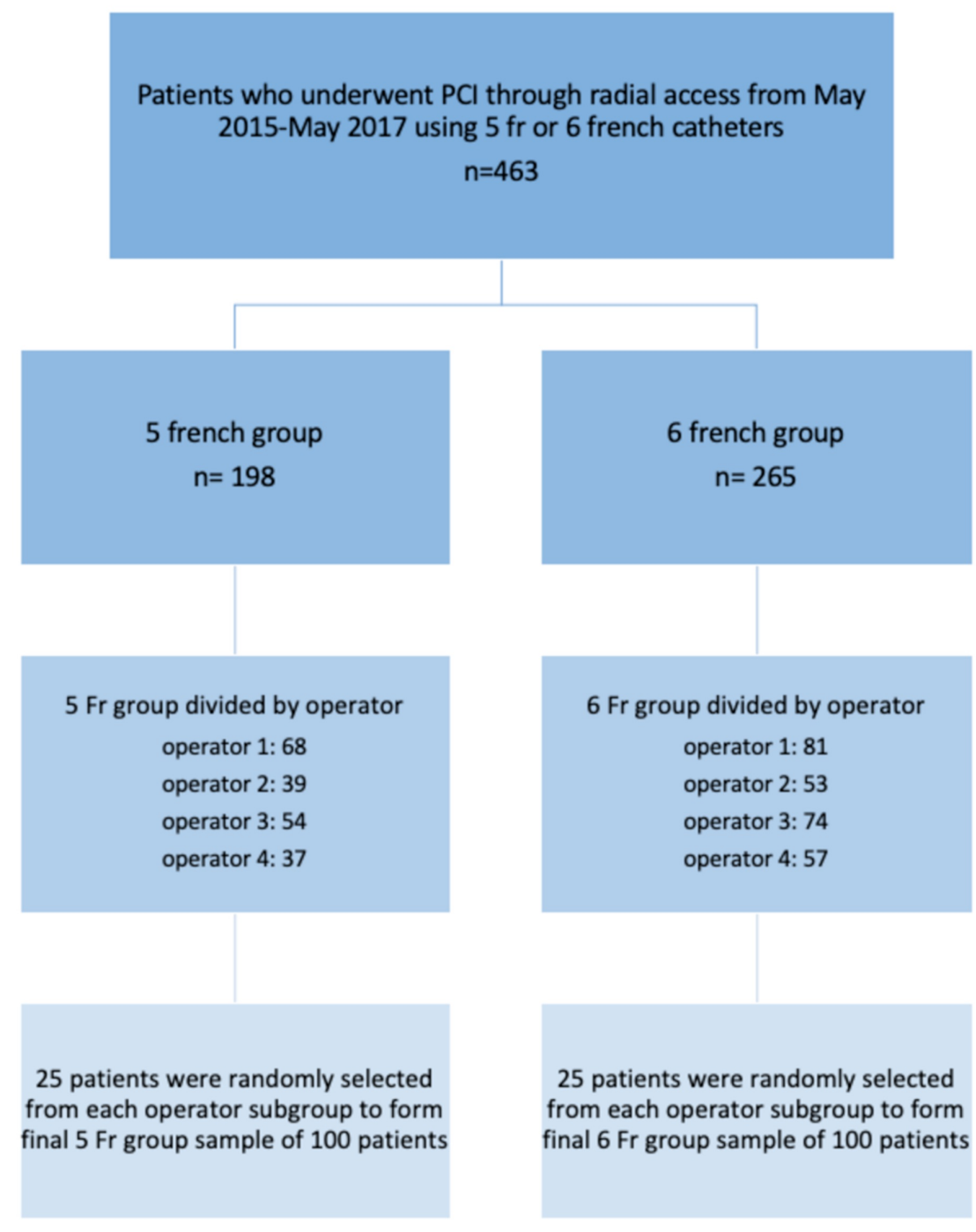

FIGURE 1: Patient population

PCI: percutaneous coronary intervention 


\section{Cureus}

\section{Procedure description}

The angioplasty procedures were performed using $5 \mathrm{Fr}$ or $6 \mathrm{Fr}$ catheters according to the operator preference and clinical judgment about the clinical condition of the patient, the coronary anatomy, and the approaching condition of the lesion. All patients were pretreated with aspirin 100-300 $\mathrm{mg}$ and were given $5000 \mathrm{IU}$ of heparin as a bolus after the insertion of the arterial sheath. An additional dose of $2500 \mathrm{IU}$ of heparin was given if the procedure lasted more than 90 mins. Balloon angioplasty followed by stent deployment was performed in all cases. At the end of each procedure, a transradial band was applied to achieve hemostasis. Procedural success was defined as a less than $50 \%$ residual stenosis with Thrombolysis in Myocardial Infarction (TIMI) grade 3 anterograde flow without the occurrence of complications such as death from any cause, urgent coronary bypass surgery, or acute myocardial infarction.

\section{Data analysis}

Baseline clinical characteristics were analyzed for all patients included in the study. Results were expressed as proportions or mean with standard deviation (SD). The primary endpoint was the amount of contrast used in the procedure. Secondary endpoints included procedure time and fluoroscopy time. All were continuous variables and they were assessed by t-test using SPSS Statistics version 24.0 (IBM, Armonk, NY). A p-value of $<0.05$ was considered statistically significant.

\section{Results}

A total of 200 patients were included in the analysis, with 100 each from the two study groups. Both groups consisted of unselected randomized patients in routine clinical practice with a diverse clinical profile. The two groups were well balanced regarding baseline characteristics (Table 1).

\begin{tabular}{|c|c|c|}
\hline Characteristics & 5 French group $(n=100)$ & 6 French group $(n=100)$ \\
\hline Males, n (\%) & $40(40 \%)$ & $77(77 \%)$ \\
\hline Females, n (\%) & $60(60 \%)$ & $23(23 \%)$ \\
\hline Age (years), mean \pm SD & $64 \pm 11.8$ & $64 \pm 11.9$ \\
\hline Hypertension, n (\%) & $82(82 \%)$ & $78(78 \%)$ \\
\hline Diabetes mellitus, $\mathrm{n}(\%)$ & $42(42 \%)$ & $40(40 \%)$ \\
\hline Chronic kidney disease, n (\%) & $9(9 \%)$ & $10(10 \%)$ \\
\hline Dyslipidemia, n (\%) & $70(70 \%)$ & $65(65 \%)$ \\
\hline Peripheral artery disease, $\mathrm{n}(\%)$ & $12(12 \%)$ & $8(8 \%)$ \\
\hline Current smoker, n (\%) & $45(45 \%)$ & $36(36 \%)$ \\
\hline Previous myocardial infarction, n (\%) & $11(11 \%)$ & $18(18 \%)$ \\
\hline
\end{tabular}

\section{TABLE 1: Demographic data and clinical characteristics}

SD: standard deviation

The mean age was 64 years in both groups with SD of 11.7 years in the $5 \mathrm{Fr}$ group and 11.9 years in the $6 \mathrm{Fr}$ group. The 5 Fr group had $40 \%$ males while the 6 Fr group had $77 \%$ males. NSTEMI was the most common indication for the procedures with $82 \%$ in the $5 \mathrm{Fr}$ group and $77 \%$ in the $6 \mathrm{Fr}$ group (Table 2). 


\section{Cureus}

\begin{tabular}{|c|c|c|}
\hline Characteristics & 5 French group $(n=100)$ & 6 French group $(n=100)$ \\
\hline Previous PCl, n (\%) & $39(39 \%)$ & $40(40 \%)$ \\
\hline Previous CABG, $\mathrm{n}(\%)$ & $27(27 \%)$ & $29(29 \%)$ \\
\hline \multicolumn{3}{|l|}{ Presentation: } \\
\hline NSTEMI, $\mathrm{n}(\%)$ & $82(82 \%)$ & $77(77 \%)$ \\
\hline STEMI, n (\%) & $8(8 \%)$ & $5(5 \%)$ \\
\hline Stable angina, n (\%) & $10(10 \%)$ & $18(18 \%)$ \\
\hline Preprocedural aspirin treatment, $\mathrm{n}(\%)$ & $100(100 \%)$ & $100(100 \%)$ \\
\hline Preprocedural GPIIb/Illa inhibitor treatment, n (\%) & $78(78 \%)$ & $69(69 \%)$ \\
\hline PCl for >1 vessel, $n$ (\%) & $20(20 \%)$ & $24(24 \%)$ \\
\hline Number of stents deployed, mean \pm SD & $1.4 \pm 1.8$ & $1.3 \pm 2.1$ \\
\hline Stent length $(\mathrm{mm})$, mean $\pm \mathrm{SD}$ & $14.8 \pm 9.3$ & $15.2 \pm 8.4$ \\
\hline Crossover trom radial to femoral access, n (\%) & $1(1 \%)$ & $3(3 \%)$ \\
\hline Group crossover, n (\%) & $3(3 \%)$ & $2(2 \%)$ \\
\hline Success rate, $(\%)$ & $99 \%$ & $98 \%$ \\
\hline
\end{tabular}

\section{TABLE 2: Angiographic characteristics}

PCI: percutaneous coronary intervention; CABG: coronary artery bypass grafting; NSTEMI: non-ST-elevation myocardial infarction; STEMI: STelevation myocardial infarction; SD: standard deviation

Crossover from $5 \mathrm{Fr}$ to $6 \mathrm{Fr}$ occurred in three cases (3\%) in the $5 \mathrm{Fr}$ group, while crossover from $6 \mathrm{Fr}$ to $5 \mathrm{Fr}$ occurred in two cases (2\%) in the $6 \mathrm{Fr}$ group. As defined in the methods section, a $99 \%$ success rate was achieved in the $5 \mathrm{Fr}$ group while $98 \%$ success rate was achieved in the 6 Fr group. Compared with transradial PCI using 6 Fr catheters, the 5 Fr group had lower contrast use $(140.2 \pm 45.7 \mathrm{~mL}$ vs. $158.2 \pm 66.7 \mathrm{~mL}$, $\mathrm{p}=0.004)$. PCI using $5 \mathrm{Fr}$ catheters was associated with shorter fluoroscopy time ( $13.7 \pm 7.3$ mins vs. $15.2 \pm 8.2$ mins, $p=0.584$ ). Again, procedure time was less with the $5 \mathrm{Fr}$ catheters $(43.7 \pm 22.2$ mins vs. $46.5 \pm 19.7$ mins, $\mathrm{p}=0.890$ ). The latter two findings were statistically insignificant.

\section{Discussion}

Initial prototypes of the $5 \mathrm{Fr}$ and $6 \mathrm{Fr}$ catheters did not have a lumen large enough for an adequate stent insertion as the lumen was less than 0.058 inches; hence, these catheters could only be employed for diagnostic purposes [5-9]. It was not until Medtronic (Medtronic plc, Dublin, Ireland) introduced a catheter with a diameter of 0.058 inches that allowed stents and balloons to pass that the potential of $5 \mathrm{Fr}$ catheters was realized [10].

The appeal of $5 \mathrm{Fr}$ catheter came to light when several studies reported favorable prospects of utilization. In 2001, Schöbel et al. reported a success rate of up to $95 \%$ in $5 \mathrm{Fr}$ catheters used in transfemoral access site depending on the type of the lesion. However, it was also reported that $5 \mathrm{Fr}$ catheters had limitations in the application such as poor back-up support in long lesions as well as severe stenosis [10]. Gobeil et al. designed a single-arm mixed study of transradial and transfemoral PCI approach that confirmed that PCIs were technically feasible using a $5 \mathrm{Fr}$ guiding catheter with a success rate of 95\% [11].

The 5 French catheter use has strongly been associated with decreased usage of contrast volume. Schussler et al. studied $5 \mathrm{Fr}$ catheters with transradial PCI in preselected cases where they were shown to be effective. They concluded that the usage of $5 \mathrm{Fr}$ catheters reduces morbidity and the cost of the procedure since it required less amount of contrast medium and resulted in minimal complications [12]. Rakhit et al. compared the $5 \mathrm{Fr}$ to $6 \mathrm{Fr}$ catheter in transfemoral PCI and found that the $5 \mathrm{Fr}$ approach is both feasible and safe with an acceptable outcome. He reported that although there does not appear to be a clear advantage in terms of vascular complications, there is a clear advantage in terms of reduced contrast medium usage with $5 \mathrm{Fr}$ catheters. The study listed several circumstances when the $5 \mathrm{Fr}$ would not be suitable, such as using cutting balloons for restenosis or kissing balloons for bifurcation lesions, but ultimately concluded that they can be effectively applied to routine interventional practice [13]. 
Gobeil et al. compared the $5 \mathrm{Fr}$ and $6 \mathrm{Fr}$ in transradial PCIs [14]. Their study had a similar design to our study, except that in our study, each operator contributed an equal amount of procedures to the total sample of each group, which eliminated the effect of inter-operator skill level differences. During this process, randomization was applied in an attempt to avoid selection bias. Contrast volume used during PCI plays an important role in the outcome of the procedure as increased contrast has been linked to increased complications including contrast-induced nephropathy. Thus, we decided to make the contrast volume our primary endpoint. Contrary to the results of Gobeil et al., our study showed that $5 \mathrm{Fr}$ catheter use was associated with less contrast volume use, which was statistically significant [14]. Procedural data analysis from both groups showed a similar average number of lesions treated and the number of stents placed. This would negate the argument that less contrast usage in the $5 \mathrm{Fr}$ group could be attributed to less complicated cases with less intervention. This could be utilized when patients with reduced kidney function require PCI. Similar to Gobeil et al., our data analysis did not show any statistically significant difference in terms of procedure time or fluoroscopy time between the two study groups.

The success of the procedure was defined as less than 50\% residual stenosis with TIMI grade 3 anterograde flow without the occurrence of complications such as death from any cause, urgent coronary bypass surgery, or acute myocardial infarction. $5 \mathrm{Fr}$ catheters were associated with a $99 \%$ success rate, which is higher than the 6 Fr group (98\%). Previous studies have shown the superiority of the use of 5 Fr catheters in terms of success and complications rates; however, the success rate of $99 \%$ is significantly higher than the rate reported in older studies like Gobeil et al., which showed a success rate of 90\% [14]. In recent years, the access site for PCI has been under debate. The transfemoral approach is recognized as the conventional approach. In the 1990s, the transradial approach was introduced as a means to decrease complications and thereby reduce the length of stay and cost [15]. Subsequently, transradial PCI was in fact shown to be superior to transfemoral PCI in reducing bleeding; however, it came with some caveats. Anatomical variations such as the smaller diameter of the radial artery, radial loops, and insufficient collateral flow are considered to be the main reasons for post-procedural complications [16]. $5 \mathrm{Fr}$ catheters become more useful in such circumstances as they are less stiff than their predecessors, thus overcoming the anatomical aberrance of the radial access [14]. The mean radial diameter ranges between just 2.20 to $2.40 \mathrm{~mm}$, making the $5 \mathrm{Fr}$ catheter the optimal choice [17]. The sheath for the $6 \mathrm{Fr}$ is $2.55 \mathrm{~mm}$, making it an unfavorable option and a potential cause for post-procedural radial artery spasm [18].

Dahm et al. conducted a randomized study of $5 \mathrm{Fr}$ vs. $6 \mathrm{Fr}$ transradial PCI aiming to ascertain whether the 5 Fr guiding catheter has equivalent procedural success and complication rates as the $6 \mathrm{Fr}$. Their study showed that transradial PCI of non-complex lesions can be successfully performed with either $5 \mathrm{Fr}$ or $6 \mathrm{Fr}$ guiding catheters, with $5 \mathrm{Fr}$ showing higher procedural success rates and lower vascular access complications in comparison to $6 \mathrm{Fr}$ guiding catheter [19]. In this study, however, data about the contrast amounts or procedure/fluoroscopy times were not collected.

\section{Conclusions}

Our findings revealed that transradial PCI using $5 \mathrm{Fr}$ guiding catheters was associated with less contrast medium usage when compared to $6 \mathrm{Fr}$ catheters. $5 \mathrm{Fr}$ catheters would thus be the preferred choice for patients with reduced renal function or when minimizing the use of contrast medium is of concern. $5 \mathrm{Fr}$ catheters did not have an advantage over $6 \mathrm{Fr}$ catheters in terms of procedure time or fluoroscopy time. Similar to $6 \mathrm{Fr}$ catheters, $5 \mathrm{Fr}$ catheters can achieve a high PCI success rate through radial access when compared in the treatment of coronary lesions with the same level of complexity.

\section{Additional Information \\ Disclosures}

Human subjects: Consent was obtained by all participants in this study. Animal subjects: All authors have confirmed that this study did not involve animal subjects or tissue. Conflicts of interest: In compliance with the ICMJE uniform disclosure form, all authors declare the following: Payment/services info: All authors have declared that no financial support was received from any organization for the submitted work. Financial relationships: All authors have declared that they have no financial relationships at present or within the previous three years with any organizations that might have an interest in the submitted work. Other relationships: All authors have declared that there are no other relationships or activities that could appear to have influenced the submitted work.

\section{References}

1. Gruntzig A: Transluminal dilatation of coronary-artery stenosis . Lancet. 1978, 1:263. 10.1016/s01406736(78)90500-7

2. Feldman R, Glemser E, Kaizer J, Standley M: Coronary angioplasty using new 6 French guiding catheters . Cathet Cardiovasc Diagn. 1991, 23:93-9. 10.1002/ccd.1810230205

3. Koch KT, Piek JJ, de Winter RJ, Mulder K, Peters RJ, David GK: Angioplasty of chronic total coronary occlusions with the use of six French guiding catheters. Cathet Cardiovasc Diagn. 1997, 40:255-60. 10.1002/(sici)1097-0304(199703)40:3<255::aid-ccd7>3.0.co;2-9

4. Urban P, Moles VP, Pande AK, Verine V, Haine E, Meier B: Percutaneous transluminal coronary angioplasty 
through six French catheters. J Invasive Cardiol. 1992, 4:335-8.

5. Chatelain P, Urban P, Camenzind E, Verine V, Hoang V, Metz D: Evaluation of the systematic use of a new type of diagnostic/interventional $6 \mathrm{~F}$ catheters for coronary angiography and angioplasty. Cathet Cardiovasc Diagn. 1994, 31:345-9. 10.1002/ccd.1810310420

6. Morís de la Tassa C, Rodríguez Lambert JL, Santos AE, Villa RB, Rodríguez Blanco VM, Alvarez VB, Llosa AC: Coronary angioplasty through 6 French guiding catheters. (Article in Spanish) . Rev Esp Cardiol. 1996, 49:124-9.

7. Resar JR, Prewitt KC, Wolff MR, Brinker JA: Coronary angioplasty through a new 6 French guiding catheter . Cathet Cardiovasc Diagn. 1994, 32:268-73. 10.1002/ccd.1810320316

8. Salinger MH, Kern MJ: First use of a 5 French diagnostic catheter as a guiding catheter for percutaneous transluminal coronary angioplasty. Cathet Cardiovasc Diagn. 1989, 18:276-8. 10.1002/ccd.1810180417

9. Villavicencio R, Urban P, Muller T, Favre J, Meier B: Coronary balloon angioplasty through diagnostic 6 French catheters. Cathet Cardiovasc Diagn. 1991, 22:56-9. 10.1002/ccd.1810220114

10. Schöbel WA, Spyridopoulos I, Hoffmeister HM, Seipel L: Percutaneous coronary interventions using a new 5 French guiding catheter: results of a prospective study. Catheter Cardiovasc Interv. 2001, 53:308-12. 10.1002/ccd.1172

11. Gobeil F, Lefèvre T, Louvard Y, Piéchaud JF, Morice MC: Coronary angioplasty using 5 French guiding catheters: preliminary experience. Catheter Cardiovasc Interv. 2000, 51:107-9. 10.1002/1522726x(200009)51:1<107::aid-ccd24>3.0.c0;2-1

12. Schussler JM, Smith R, Schreibfeder M, Hill D, Anwar A: Five French (5 Fr) guiding catheters for percutaneous coronary angioplasty and stent placement: an initial feasibility study. Catheter Cardiovasc Interv. 2000, 51:352-7. 10.1002/1522-726x(200011)51:3<352::aid-ccd26>3.0.c0;2-0

13. Rakhit RD, Matter C, Windecker S, Garachemani AR, Seiler C, Eberli FR: Five French versus 6 French PCI: a case control study of efficacy, safety and outcome. J Invasive Cardiol. 2002, 14:670-4.

14. Gobeil F, Brück M, Louvard Y, Levèvre T, Morice MC, Ludwig J: Comparison of 5 French versus 6 French guiding catheters for transradial coronary intervention: a prospective, randomized study. J Invasive Cardiol. 2004, 16:353-5.

15. Kiemeneij F, Laarman GJ, de Melker E: Transradial artery coronary angioplasty. Am Heart J. 1995, 129:1-7. 10.1016/0002-8703(95)90034-9

16. Saito S, Ikei H, Hosokawa G, Tanaka S: Influence of the ratio between radial artery inner diameter and sheath outer diameter on radial artery flow after transradial coronary intervention. Catheter Cardiovasc Interv. 1999, 46:173-8. 10.1002/(SICI)1522-726X(199902)46:2<173::AID-CCD12>3.0.CO;2-4

17. Gobeil F, Barbeau GR: Ultrasonic assessment of radial atherosclerotic changes following transradial angiography/angioplasty procedure in diabetic patients. Circulation. 1999, 1:2-5.

18. Barbeau GR, Carrier G: Predictors of radial artery thrombosis after transradial approach: a multivariate analysis of a large series. Can J Cardiol. 1999, 175:1-4

19. Dahm JB, Vogelgesang D, Hummel A, Staudt A, Völzke H, Felix SB: A randomized trial of 5 vs. 6 French transradial percutaneous coronary interventions. Catheter Cardiovasc Interv. 2002, 57:172-6.

10.1002/ccd.10321 